\title{
Supracondylar Transjugular'Tubercle Approach to Intradural Lesions Anterior or Anterolateral to the Craniocervical Junction without Resection of the Occipital Condyle
}

\author{
Kraniyoservikal Bileşke Anterior veya Anterolateralindeki Intradural \\ Lezyonlarda Oksipital Kondil Rezeksiyonu Yapulmadan Suprakondiler \\ Transjuguler Tüberkül Yaklaşımı
}

Li MEI-HUA, Xu GENG-SHENG, Jiang ZHI-QUN, Li YI-YUN, Hong TAO

The Affiliated Hospital of Nanchang University, Department of Neurosurgery, Nanchang 330006, P.R. China

Correspondence address: Li MEI-HUA / E-mail: meihualicn@yeah.net

\begin{abstract}
AIM: To clarify the usefulness of supracondylar transjugular tubercle approach for treatment intradural lesions anterior and anterolateral to foramen magnum, in which the posterior portion of the jugular tubercle is removed extradurally through the condylar fossa with the atlantooccipital joint intact.

MATERIAL and METHODS: The supracondylar transjugular tubercle approach was applied to 28 craniocervical junction surgeries. These surgeries included clipping a vertebral artery aneurysm in 12 cases and removing intradural tumors ventral and ventrolateral to foramen magnum in 16 cases.

RESULTS: The approach offered very good visualization of the anterior and anterolateral part of the craniocervical junction region and sufficient working space. These surgeries were performed safely without major complications. In all 12 cases, the aneurysm was easily clipped without any problems. In 16 cases of tumors, 14 tumors were totally removed, the remaining 2 cases achieved subtotal resection due to medullary invasion of tumors.

CONCLUSION: Supracondylar transjugular tubercle approach offered very good visualization of the anterior and anterolateral part of the craniocervical junction region and can be an ideal approach for accessing intradural lesions anterior and anterolateral part of the craniocervical junction region.
\end{abstract}

KEYWORDS: Supracondylar transjugular tubercle approach, Intradural lesions, Craniocervical junction region

öz

AMAÇ: Foramen magnuma anterior ve anterolateral intradural lezyonların tedavisinde atlanto-oksipital eklem sağlam bırakılarak kondiler fossa içinden ekstradural olarak juguler tüberkülün posterior kısmının çıkarıldığı suprakondiler transjuguler tüberkül yaklaşımının faydasını açığa kavuşturmak.

YÖNTEM ve GEREÇLER: Suprakondiler transjuguler tüberkül yaklaşımı 28 kraniyoservikal bileşke cerrahisinde uygulandı. Bu cerrahiler arasında 12 vakada bir vertebral arter anevrizmasının klipslenmesi ve 16 vakada foramen magnuma ventral ve ventrolateral intradural tümörlerin çıkarılması vardı.

BULGULAR: Bu yaklaşım kraniyoservikal bileşke bölgesinin anterior ve anterolateral kısmının çok iyi görüntülenmesini mümkün kıldı ve yeterli çalışma alanı sağladı. Bu cerrahiler majör komplikasyon olmadan güvenli bir şekilde yapıldı. 12 vakanın tümünde anevrizma herhangi bir problem olmadan kolayca klipslendi. 18 tümör vakasında 14 tümör tamamen çıkarıldı ve kalan 2 vakada tümörlerin medüller invazyonu nedeniyle subtotal rezeksiyon yapıldı.

SONUÇ: Suprakondiler transjuguler tüberkül yaklaşımı kraniyoservikal bileşke bölgesinin anterior ve anterolateral kısmında çok iyi görüntülenme sağladı ve kraniyoservikal bileşke bölgesinin anterior ve anterolateral kısmındaki intradural lezyonlara erişimi için ideal bir yaklaşım olabilir.

ANAHTAR SÖZCÜKLER: Suprakondiler transjuguler tüberkül yaklaşımı, İntradural lezyonlar, Kraniyoservikal bileşke bölgesi 


\section{INTRODUCTION}

The craniocervical junction area is generally defined as the region between the lower third of the clivus and the superior rim of the C2 vertebral arch, and is a common site for various lesions, such as vascular, neoplastic, and degenerative pathologies (3-5). Despite technique improvements, the microsurgical management of lesions in this area remains a challenge due to the complex topographical anatomy. The majority of craniocervical lesions are located predominantly posterior or posterolateral to the lower brainstem and upper cervical cord; nevertheless, quite a number of tumors and vascular lesions are found anterior or anterolateral to the neuraxis (3). The former lesions may easily be accessed by the traditional posterior approach comprising a median suboccipital craniotomy that includes opening of the posterior foramen magnum and, depending upon the size and extent of the lesion, sometimes also including a C1 or even a C2 laminectomy $(3,4)$. The latter lesions cannot adequately be accessed by this standard posterior approach without the risk of injuring the neuraxis or the rootlets of the lower cranial nerves $(3,5)$. These lesions can best be approached via the dorsolateral access route.

Multiple variations of the suboccipital approach had been elaborated and published in the 1980s and early 1990s since Seeger firstly described a dorsolateral approach to the vertebrobasilar junction and used the term "transcondylar" in $1978(10,11,22)$. The far-lateral transcondylar approach has been widely used to treat these lesions anterior or anterolateral to the neuraxis because it can provide better visualization of ventral structures without retraction (3$5,10,11,22)$. However, the disadvantages of the transcondylar approach include lengthening of the surgical procedure, increased postoperative pain, possible VA and hypoglossal nerve injury, and some loss of craniocervical stability (18). Recently, a few authors $(13,15,18)$ have reported that it is not necessary to resect the occipital condyle to remove tumors in this region. Here, we describe a modified far-lateral approachsupracondylar transjugular tubercle approach, which was performed to treat 28 lesions anterior and anterolateral to the craniocervical junction without resecting the occipital condyle.

\section{MATERIAL and METHODS}

\section{Patients}

The study was approved by the Institutional Review Board of Nanchang University, China. Between January 2001 and March 2011, 28 patients underwent surgery for lesions of the anterior and anterolateral to the craniocervical junction by use of supracondylar transjugular tubercle approach in the Department of Neurosurgery, the First Affiliated Hospital of Nanchang University, China. This study was conducted in accordance with the declaration of Helsinki and under approval from the Ethics Committee of the affiliated hospital of Nanchang University. Written informed consent was obtained from all participants. Clinical and operative records, radiological findings, and follow-up records were reviewed retrospectively. The surgeries included removing intradural tumors of the anterior and anterolateral to the craniocervical junction in 16 cases, clipping a vertebral artery-posterior inferior cerebellar artery aneurysm or fusiform vertebral artery aneurysm in 12 cases. The 28 patients included 9 males and 19 females. Their ages ranged from 18 to 70 years (mean, 48.6 years). Presenting symptoms and signs included headache or occipital pain in 17 patients, quadriparesis in 10, lower cranial nerve deficits in 4, extremity paresis, hemiparesis, and dizziness in 2 patients each. No patient had undergone prior resection of tumor in the craniocervical junction area.

\section{Surgical procedures}

We modified and refined classic transcondylar and transcondylar fossa techniques, which were first described by Bertalanffy in 1991 (3-5) and Matsushima in 1996 (1316), respectively. Briefly, after general anesthesia had been induced, each patient was placed in the park bench position with the patient's head fixed in slight flexion and rotated to the contralateral side. Venous congestion should be considered to avoiding intraoperative profuse venous bleeding. Intraoperative electrophysiological monitoring, including somatosensory, auditory evoked potentials, and cranial nerve EMG was performed in some patients. We used a slight curvilinear or straight skin incision between the mastoid and midline in the retroauricular area, as described by Bertalanffy $(3,4)$. Skin incision was followed by detaching the muscle insertions on the superior nuchal line and mastoid, with the sternocleidomastoid and splenius capitis muscles laterally and trapezius and semispinal capitis muscles medially. We usually do not obtain an anatomical exposure of the deep muscle triangle that is formed by the rectus capitis posterior major, and the superior and inferior oblique capitis muscles. The posterior lateral part of the atlantal arch and the horizontal portion of the vertebral artery lie within this triangle. Palpating the sharp dorsal lateral rim of the atlantal arch is the best procedure to identify the artery at an early stage of this exposure $(3,5)$. Once the periosteal sheath of the atlantal arch is dissected sharply, the exact location of the vertebral loop is confirmed. It becomes easy to detach the rectus capitis posterior major and minor and the superior oblique muscles from the inferior nuchal line and to gradually expose the supracondylar fossa and the posterior rim of the foramen magnum. The posterior condylar emissary vein in the condylar fossa is found and coagulated and cut. The craniocaudal extension of the exposure depends upon the underlying lesion. Usually, exposure of the atlantal arch is sufficient. Next, a routine retrosigmoid craniotomy is done, which is gradually extended medially and caudally to include the foramen magnum. The posterior part of the foramen magnum is completely opened but the laminectomy differs from case to case (3-5). A hemilaminectomy of $C 1$ (12 patients) or of C1 and C2 (1 patient) was tailored to the caudal extent of the tumor in the upper cervical spinal canal in our series. Then, gently detaching the dura mater laterally, one can identify the distal sigmoid sinus and proximal jugular bulb, which is a good landmark that indicates the lateral limit of this exposure. 
The condylar fossa superior to the posterior condylar canal, which is the posterior portion of the jugular tubercle, is drilled extradurally and removed with the canal in sight as an anatomic landmark (13-16). The key point of our preferred approach is the bony removal along the canal anteriorly resulting in removing the posterior part of the jugular tubercle and the atlanto-occipital joint can be kept intact $(13,15)$. We prefer to open the dura mater in a longitudinal fashion, the lower part of the incision being placed medial to the vertebral artery. The cisterna magna is opened to drain the CSF. The dentate ligament was sectioned before initiating tumor removal to release tension on the neuraxis and to widen surgical access to the tumor. The origin of the posterior inferior cerebellar artery and the entire courses of the 9th and 10th cranial nerves are visible. With a slight retraction of the cerebellum after the lateral portion of the cerebellomedullary fissure is dissected, the operative working space becomes larger (9). The exposure described above provides the optimal straightline view to the anterolateral aspect of the lower brainstem and upper cervical cord without the need to retract the neuraxis or damage the rootlets of the lower cranial nerves $(9,15)$. Then, the aneurysms and tumors anterior or anterolateral to craniocervical junction can be exposed and managed easily.

\section{RESULTS}

Of the 16 patients harboring lesions in the anterior or anterolateral craniocervical junction and the 12 patients with VA aneurysms, all 28 experienced good clinical outcomes. The 16 case with tumors in the anterior or anterolateral craniocevical junction included 12 of meningioma, 2 of neurinoma, 1 of oligodendroglioma and 1 of ependymoma. The supracondylar transjugular tubercle approach was

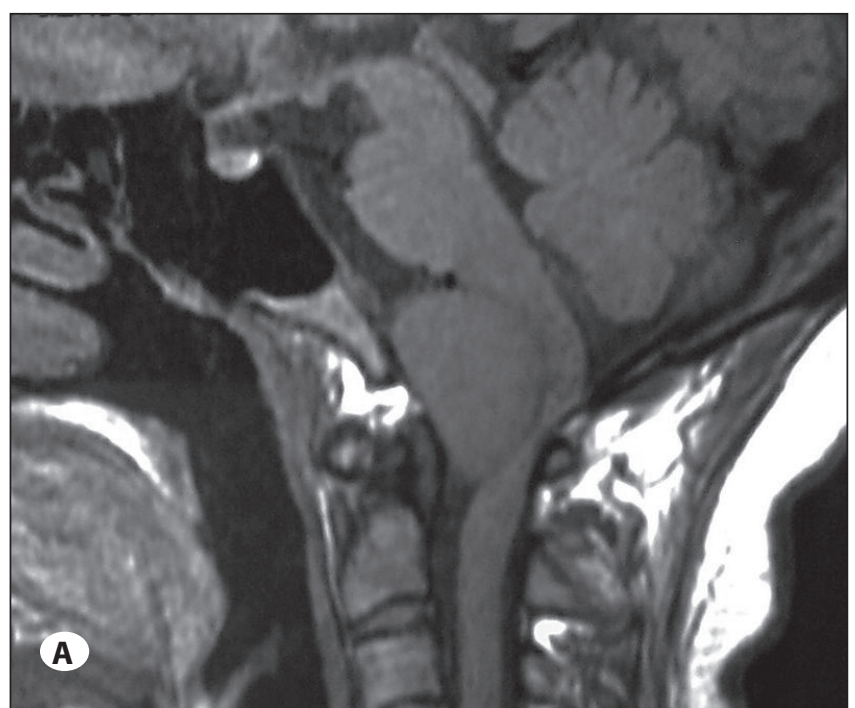

combined with the cerebellomedullary fissure approach in 1 case with oligodendrioglioma and 1 with ependymoma. Total removal was achieved in 14 cases, subtotal removal in 2 cases with ependymoma or oligodendroglioma. In 12 cases with VA aneurysms, the saccular VA-PICA aneurysm in 10 cases was easily clipped and the fusiform VA aneurysm in the remaining 2 cases was successfully trapped through the supracondylar transjugular tubercle approach. The 12 cases included 9 ruptured and 3 unruptured aneurysms. The postoperative complications included mild subcutaneous fluid collection in 3 cases and temporary hoarseness in 2 cases, which were resolved completely by 3 and 6 months after surgery, respectively. No patients experienced CSF leaks or infections. No permanent complication occurred. After 6 months to 10 years follow-up (mean 4.6 years), no tumor recurrence was observed. Two patients with residual tumor, who had radiotherapy after surgery, had the tumor controlled. All patients improved neurologically.

\section{Illustrative cases}

\section{Case 1}

A 41-year-old woman was admitted with gait disturbance and progressive weakness in her extremities. The neurologic examination showed quadriparesis, hypertonia and hyperreflexia. The magnetic resonance imaging demonstrated a meningioma anterior to craniocervical junction and partial encasement of VA was present (Figure $1 \mathrm{~A}, \mathrm{~B}$ ). The patient underwent surgery for tumor removal via the supracondylar transjugular tubercle approach without resection of the occipital condyle. Total tumor removal was performed, and the postoperative course was uneventful. Histopathological analysis confirmed the diagnosis of meningioma. The patient was discharged with great improvement of her previous

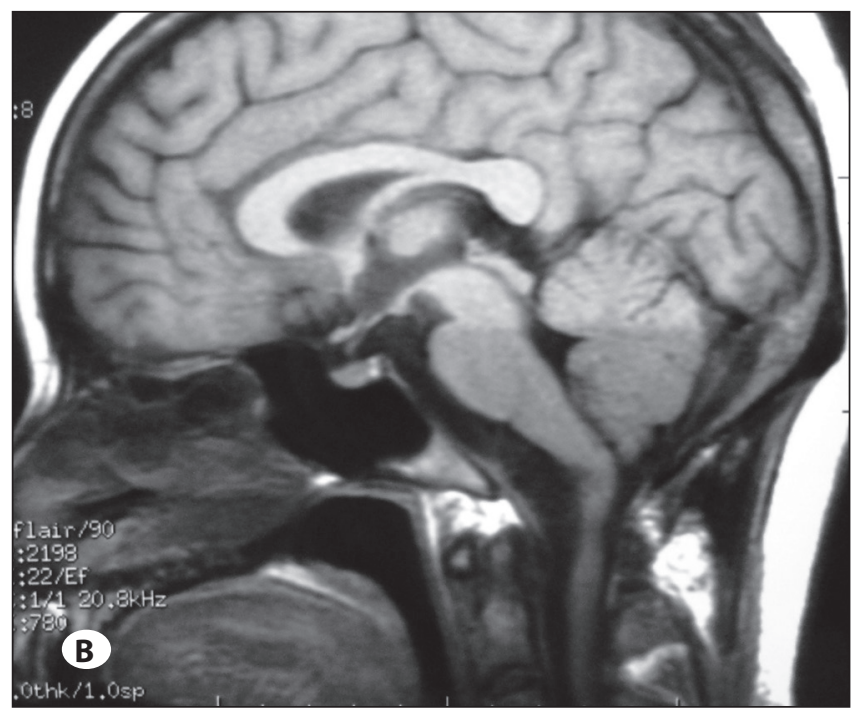

Figure 1: A 41-year-old woman was admitted with gait disturbance and progressive weakness in her extremities. The preoperative magnetic resonance imaging demonstrated a meningioma anterior to craniocervical junction and partial encasement of VA was present. The patient underwent surgery for tumor removal via the supracondylar transjugular tubercle approach without resection of the occipital condyle. Total tumor removal was performed, and the postoperative course was uneventful. Histopathological analysis confirmed the diagnosis of meningioma. 
symptoms. At the 1-year follow-up visit, she was neurologically intact and magnetic resonance imaging demonstrated no residual tumor (Figure 1).

\section{Case 2}

A 56-year-old male presented to our department with progressive dysphagia, quadriparesis and gait disturbance. Neurological examination demonstrated global hyperreflexia and lower cranial nerve deficits. Magnetic resonance imaging revealed an intraaxial tumor located anterolateral to the craniocervical junction. The lesion was subtotally removed via the supracondylar transjugular tubercle approach combined with transcerebellomedullary approach (Figure 2 A,B). After the supracondylar transjugular tubercle approach, with retraction of the tonsil, the lateral part of the cerebellomedullary fissure was dissected and opened. This dissection provided views of the cerebellomedullary cistern and the fourth ventricle while necessary. Postoperative course was uneventful. Histopathological analysis revealed a diagnosis of oligodendroglioma. At the 3-year follow-up examination, he reported great improvement of his previous neurological deficits and having resumed his regular activities.

\section{DISCUSSION}

Surgery for lesions anterior or anterolateral craniocervical junction has been associated with high risks of morbidity and mortality. The far-lateral approach and its modifications provide access to the upper ventral spinal canal, the anterior portion of the foramen magnum, the lower and middle clivi $(4,10,11,22)$. It has been used to gain access to the craniovertebral junction to treat intradural tumors $(17,23,24)$, nonneoplastic lesions (1), and vascular diseases $(7,12)$. Modifications of the far-lateral approach are based on the extent of bone removal. For example, Salas et al (21) demonstrated six variations of the extreme-lateral craniocervical approach based on the bone removed. However, generally speaking, the far lateral approach can be subdivided into the transcondylar approach and the condylar fossa approach. Transcondylar approach involves resection of some or all of the occipital condyle. Bertalanffy and Seeger (3-5) pointed that the posteromedial portion of the occipital condyle and lateral mass of the atlas should be drilled away and that the drilling should then be continued anteriorly to expose the hypoglossal canal and cranially until the jugular tubercle is resected. The key step of the condylar fossa approach is drilling of the condylar fossa and the posterior part of the jugular tubercle (15). Recently both Wu (26) and Spektor (19) evaluated the transcondylar approach and the condylar fossa approach based on quantitative measurements of the exposure of the craniocervical junction area. It was concluded that the transcondylar approach and the condylar fossa approach provided similar exposures of petroclivus and brainstem when the jugular tubercle and occipital condyle were not prominent, the partial condylectomy improved visualization of ventral structures of neuraxis insignificantly, except for lesions below the hypoglossal canal, which the transcondylar approach was preferred because it significantly
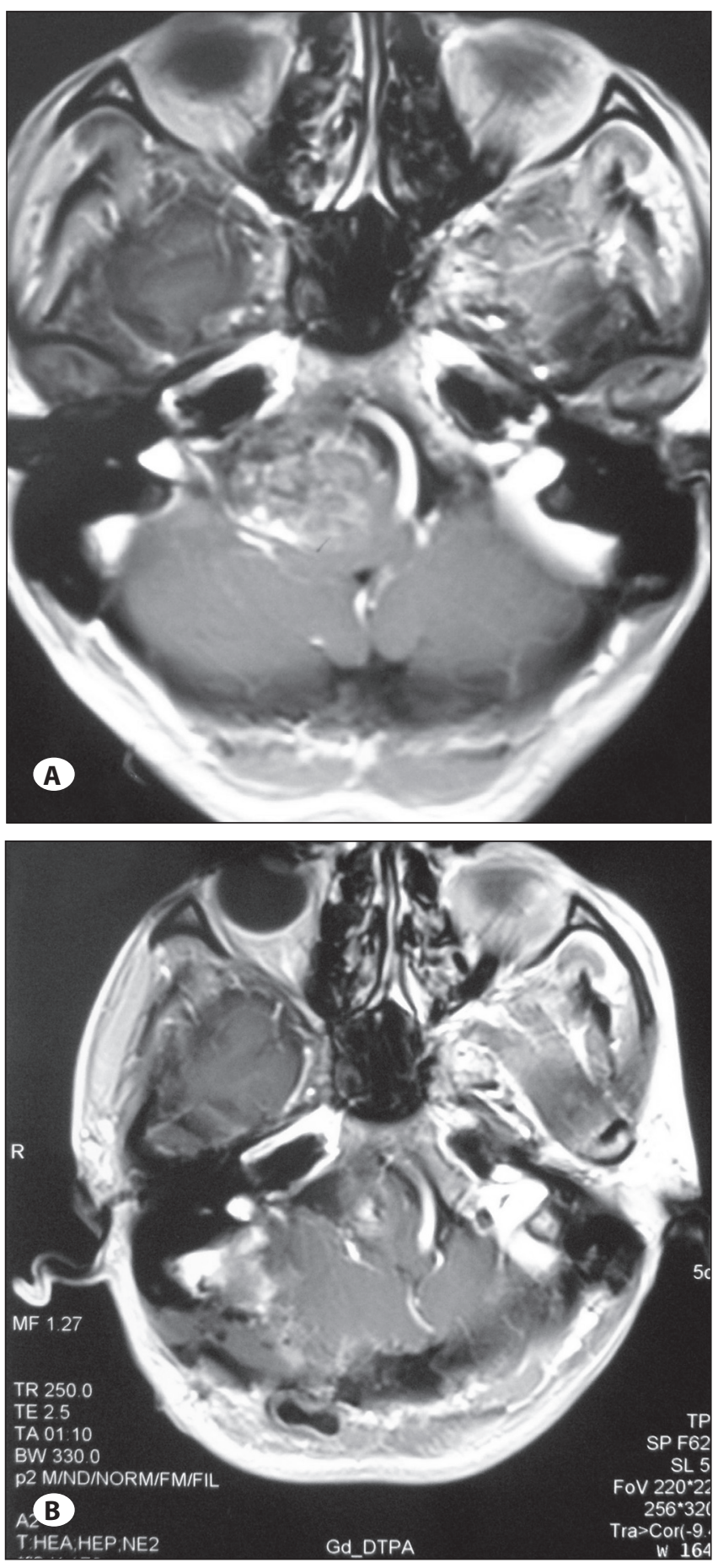

Figure 2: A 56-year-old male presented to our department with progressive dysphagia, quadriparesis and gait disturbance. Preoperative magnetic resonance imaging revealed an intraaxial tumor located anterolateral to craniocervical junction. The lesion was subtotally removed via the supracondylar transjugular tubercle approach combined with transcerebellomedullary approach.Postoperativecoursewasuneventful. Histopathological analysis revealed a diagnosis of oligodendroglioma. 
increased the angle of attack $(25,26)$. And the most dramatic increase in the exposure of craniocervical junction region was noted after removal of the jugular tuberculum (25).

With the coming of age of skull base surgery, the enthusiasm for extensive bone resection has made drilling the occipital condyle a usual part of any approach to craniocervical junction area, but it comes at a price (18). It increases the duration of operation time, the incidence of a CSF leak, and may result in cranial nerve injury and craniocervical instability (18). Matsushima et al (13) in 1996, first proposed the supracondylar transjugular approach, which can also be called the transcondylar fossa approach. They has applied this approach to surgery for VA-PICA aneurysm $(15,16)$, microvascular decompression for glossopharyngeal neuralgia $(14,15)$, and removal of intradural tumors around the jugular tubercle or the hypoglossal canal (9). Gilsbach et al (8) also reported the supracondylar approach as a minimally invasive extradural approach. Perneczky's posterolateral approach (19) and Salas' retrocondylar approach (21) are also almost similar to the transcondylar fossa approach. The most important point, when applying the supracondylar transjugular approach is drilling of the condylar fossa, namely, the posterior portion of the jugular tubercle extradurally and the the atlanto-occipital joint should kept intact (13-16). The posterior condylar canal and the emissary vein in the canal both play an important role as intraoperative anatomic landmarks differentiating the jugular tubercle and the occipital condyle from outside (15). The supracondylar transjugular approach provides an entire view of the cerebellomedullary cistern including the VA, the anterior and lateral medullary segments of the PICA, and the cisternal portion of the 9th, 10th, 11th and 12th cranial nerves (13-16). Furthermore, when the cerebellomedullary fissure is dissected, the surgical field becomes larger and the lateral part of the fourth ventricle can be exposed $(13,15)$. We have used the supracondylar transjugular approach to surgery for intradural lesions anterior or anteriolateral to craniocervical junction area, including tumors and VA aneurysms.

In all tumor cases, the tumors could be removed via the supracondylar transjugular approach without resection of the occipital condyle and removing the condyle seemed to be unnecessary. However, in 2 cases with intraaxial tumor, this approach was further combined with transcerebellomedullary fissure approach to remove the tumor, which extended to the cerebellomedullary fissure and the lateral part of the fourth ventricular cavity. In our series of 16 cases with tumors anterior or anterolateral to craniocervical junction area, 14 patients with meningioma or neurinoma were performed total tumor removal, while 2 patients, 1 of oligodendroglioma and 1 of ependymoma, underwent subtotal tumor resection due to the poor dissection plane. Nanda (18) and Bassiouni (2) also reported total removal of meningioma at the foramen magnum without resection of the occipital condyle. These studies above, along with our report, suggest that more extensive bone removal is usually unnecessary for intradural tumors anterior or anteriolateral craniocervical junction area because displacement of the brainstem by the lesion provides enhanced anterior visualization.
For VA aneurysms, the supracondylar transjugular tubercular approach provided an excellent access route to expose this group of difficult aneurysms of the posterior circulation. It not only offered good control of the vertebral artery proximal to the aneurysm but also gave good access to the distal portion of the artery up to the vertebrobasilar junction $(15,16)$. Both Bertalanffy et al (5), who used the transcondylar approach, and Matsushima et al (13-16), who used the transcondylar or transcondylar fossa approach, reported that operative morbidity and mortality were relatively low. Matsushima also noted (16) that surgical approach for VA aneurysms depended on the locations of aneurysms, when an aneurysm was located in the midline or below the hypoglossal canal, the transcondylar approach was preferred. We have employed the supracondylar transjugular approach for VA aneurysm surgery. In our series, neck clipping or trapping could be done in all of 12 VA aneurysms, including 10 VA-PICA aneurysms and two fusiform VA aneurysms. There was no permanent morbidity except one patient experienced a temporary hoarseness that completely recovered 3 months after surgery.

\section{Pitfalls of the approach}

During position, care must be taken to avoid compression of the jugular vein. The patient should be positioned with the head rotated ipsilaterally and flexed so that the posterior portion of the occipital condyle articular facet becomes visible during surgery (3). Special attention must be paid to avoid the bleeding from venous plexus around VA. Injection of fibrin glue into the periarterial or epidural venous plexus is helpful measures to maintain a bloodless surgical field $(3,5)$. At an early stage of the exposure, the exact location of the vertebral artery should be identified by palpating the posterior sharp edge of the atlantal arch (3). Utmost care should be taken during retraction of the VA because a muscular branch of the vertebral artery emerges from its lateral horizontal loop in some cases and forceful retraction may cause dissection or thrombosis of the artery (3). However, when a lesion, especially an aneurysm, was located in the midline or below the hypoglossal canal, the supracondylar transjugular approach had to be changed to the transcondylar approach (15).

In a conclusion, lesions anterior and anterolateral to the craniocervical junction present a formidable surgical challenge. The enthusiasm for extensive bone removal has made drilling the occipital condyle a customary part of any approach to this region (18). We report here that the supracondylar transjugular tubercular approach, where the posterior portion of the jugular tubercle is drilled but the occipital condyle is kept intact, has been employed to gain the required exposure for lesions in this area, not only for intradural tumors, but also for vascular cases in which good visualization can similarly be provided. Based on the result of our small series, resection of the occipital condyle should not be considered a technique imperative and usually unnecessary for surgery of lesions anterior and anterolateral to the craniocervical junction. 


\section{REFERENCES}

1. Al-Mefty O, Borba LA, Aoki N, Angtuaco E, Pait TG: The transcondylar approach to extradural nonneoplastic lesions of the craniovertebral junction. J Neurosurg 84:1-6, 1996

2. Bassiouni H, Ntoukas V, Asgari S, Sandalcioglu El, Stolke D, Seifert V: Foramen magnum meningiomas: Clinical outcomes after microsurgical resection via a posterolateral suboccipital retrocondylar approach. Neurosurgery 59:1177-1187, 2006

3. Bertalanffy $H$, Bozinov O, Sürücü O, Sure U,Benes L, Kappus C: Dorsolateral approach to the craniocervical junction. In: Cappabianca P (ed.), Cranial, Cranio-Facial and Skull Base Surgery. Italia: Springer-Verlag, 2010:175-195

4. Bertalanffy $H$, Seeger W: The dorsolateral, suboccipital, transcondylar approach to the lower clivus and anterior portion of the craniocervical junction. Neurosurgery 29: 815-821, 1991

5. Bertalanffy $H$, Sure U, Petermeyer M, Becker R, Gilsbach JM: Management of aneurysms of the vertebral artery-posterior inferior cerebellar artery complex. Neurol Med Chir (Tokyo) 38 (Suppl): 93-103, 1998

6. Bruneau M, George B: Foramen magnum meningiomas: Detailed surgical approaches and technical aspects at Lariboisière Hospital and review of the literature. Neurosurg Rev 31: 19-32, 2008

7. Day JD, Fukushima T, Giannotta SL: Cranial base approaches to posterior circulation aneurysms. J Neurosurg 87:544-554, 1997

8. Gilsbach JM, Sure U, Mann W: The supracondylar approach to the jugular tubercle and hypoglossal canal. Surg Neurol 50: 563-570, 1998

9. Kawashima M, Matsushima T, Nakahara Y, Takase Y, Masuoka J, Ohata K: Trans-cerebellomedullary fissure approach with special reference to lateral route. Neurosurg Rev 32:457-464, 2009

10. Kawashima M, Tanriover N, Rhoton AL Jr, Ulm AJ, Matsushima $\mathrm{T}$ : Comparison of the far lateral and extreme lateral variants of the atlanto-occipital transarticular approach to anterior extradural lesions of the craniovertebral junction. Neurosurgery 53: 662-674, 2003

11. Lanzino G, Paolini S, Spetzler RF: Far-lateral approach to the craniocervical junction. Neurosurgery 57 (4 Suppl): 367-371, 2005

12. Lawton MT, Daspit CP, Spetzler RF: Technique aspects and recurrent trends in management of large and giant midbasilar artery aneurysms. Neurosurgery 41:513-521, 1997

13. Matsushima T, Fukui M: Lateral approaches to the foramen magnum: With special reference to the transcondylar fossa approach and the transcondylar approach. No Shinkei Geka 24:119-124, 1996
14. Matsushima T, Goto Y, Natori Y, Matsukado K, Fukui M: Surgical treatment of glossopharyngeal neuralgia as vascular compression syndrome via transcondylar fossa (supracondylar transjugular tubercle) approach. Acta Neurochir (Wien) 142: 1359-1363, 2000

15. Matsushima T, Kawashima M, Masuoka J, Mineta T, Inoue T: Transcondylar fossa (Supracondylar Transjugular Tubercle) approach: Anatomic basis for the approach, surgical procedures, and surgical experience. Skull Base 20:83-91, 2010

16. Matsushima T, Matsukado K, Natori Y, Inamura T, Hitotsumatsu T, Fukui M: Surgery on a saccular vertebral artery-posterior inferior cerebellar artery aneurysm via the transcondylar fossa (supracondylar transjugular tubercle) approach or the transcondylar approach: Surgical results and indications for using two different lateral skull base approaches. J Neurosurg 95: 268-274, 2001

17. Menezes AH: Surgical approaches: Postoperative care and complications "posterolateral-far lateral transcondylar approach to the ventral foramen magnum and upper cervical spinal canal". Childs Nerv Syst 24:1203-1207, 2008

18. Nanda A, Vincent DA, Vannemreddy PS, Baskaya MK, Chanda A: Far-lateral approach to intradural lesions of the foramen magnum without resection of the occipital condyle. J Neurosurg 96: 302-309, 2002

19. Perneczky A: The posterolateral approach to the foramen magnum. In: Samii M (ed) Surgery in and around the Brain Stem and the Third Ventricle. Berlin: Springer, 1986:460-466

20. Rhoton AL Jr: The far-lateral approach and its transcondylar, supracondylar, and paracondylar extensions. Neurosurgery 47 (Suppl 1): S195-S209, 2000

21. Salas E, Sekhar LN, Ziyal IM, Caputy AJ, Wright DC: Variations of the extreme-lateral craniocervical approach: Anatomical study and clinical analysis of 69 patients. J Neurosurg 90(2 Suppl): 206-219, 1999

22. Seeger W: Atlas of topographical anatomy of the brain and surrounding structures. Vienna: Springer, 1978: 486-489

23. Sen CN, Sekhar LN: An extreme lateral approach to intradural lesions of the cervical spine and foramen magnum. Neurosurgery 27:197-204, 1990

24. Sen CN, Sekhar LN: Surgical management of anteriorly placed lesions at the craniocervical junction: An alternative approach. Acta Neurochir (Wien) 108:70-77, 1991

25. Spektor S, Anderson GJ, McMenomey SO, Horgan MA, Kellogg JX, Delashaw JB Jr: Quantitative description of the far-lateral transcondylar transtubercular approach to the foramen magnum and clivus. J Neurosurg 92:824-831, 2000

26. Wu AH, Zabramski JM, Jittapiromsak P, Wallace RC, Spetzler RF, Preul MC: Quantitative analysis of variants of the farlateral approach: Condylar fossa and transcondylar exposure. Neurosurgery 66 (Suppl 2):191-198, 2010 